\section{Where should ascitic drains be placed? Revisiting anatomical landmarks for paracentesis}

We welcome the recent publication of the BSG/BASL guidelines on the management of ascites in cirrhosis which will serve as a framework for patient management across the world. ${ }^{1}$ Following clinician feedback on Twitter, ${ }^{2}$ we wish to respectfully highlight concerns regarding their guidance on landmarks for therapeutic paracentesis.

Our first concern relates to the description of the landmarks. The authors recommend this to be 'at least $8 \mathrm{~cm}$ (laterally) from the midline and $5 \mathrm{~cm}$ above the symphysis (pubis)'. ${ }^{1}$ This was predicated on three studies (two laparoscopic; one cadaveric) on the anatomical course of the inferior epigastric artery. ${ }^{3-5}$ While this approach avoids puncturing the vessel, there remains a risk of injury to underlying solid organs which can result in haemorrhage or perforation. Of note, these studies may not be generalisable to patients with distortion of the abdominal cavity due to gross ascites.

Second, the figures depicting the landmarks for paracentesis require clarification. In Figure 4A of the published paper, ${ }^{1}$ the umbilicus appears closer to the subcostal plane than the symphysis pubis; this is not anatomically representative. The safe zones (denoted in green) appear too superior and lateral; these exceed the ' $5 \mathrm{~cm}$ above the symphysis' description which is ambiguous, and should stipulate an upper bound distance. In Figure $4 \mathrm{~B}$ of the published paper, ${ }^{1}$ the paracentesis site 


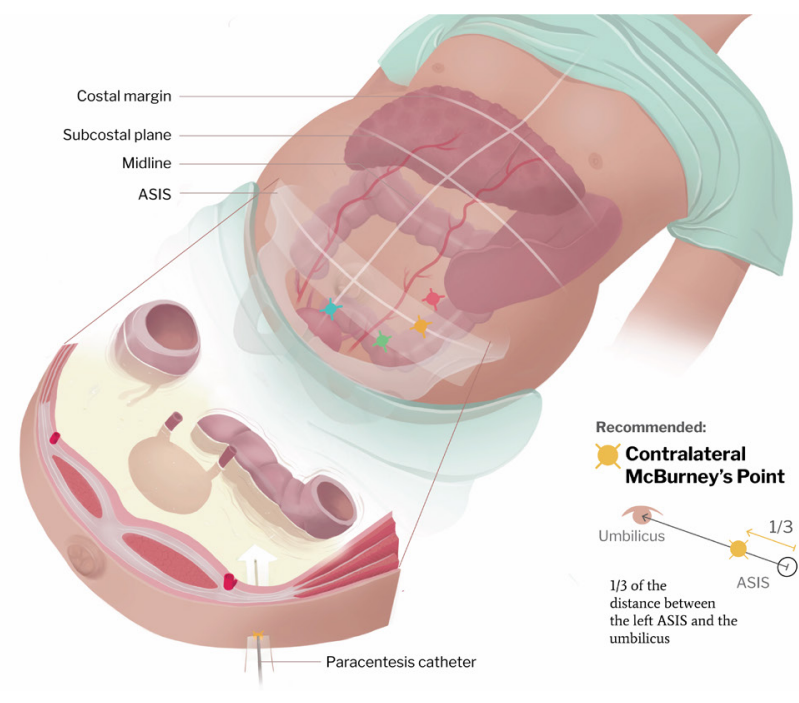

Where should ascitic drains be placed?

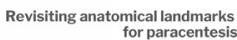

Figure 1 Anatomical landmarks for paracentesis. ASIS, anterior superior iliac spine.

photographed corresponds to the diagram but appears too superior and lateral to be considered safe without ultrasound guidance, as this carries a risk of splenic injury and bowel perforation.

Patient safety must always be prioritised. Ultrasound guidance mitigates the risks of paracentesis-related complications, but its availability is limited in resourcepoor settings and in some UK hospitals. Training in bedside ultrasound is also variable. Moreover, with the COVID-19 pandemic, transporting ultrasound machines between patients and across sites risks transmission. Thus, it remains important to teach paracentesis landmarks in a clear and safe manner without sole reliance on ultrasound.

Conventional teaching places emphasis on the following landmarks for paracentesis: (i) in relation to the anterior superior iliac spine (ASIS): $5 \mathrm{~cm}$ superiorly and medially; ${ }^{6}$ (ii) left or right lower quadrants: $2-3 \mathrm{~cm}$ lateral to the inferior rectus sheath border, ${ }^{7}$ (iii) midline approach within the linea alba: $2 \mathrm{~cm}$ below the umbilicus (this is unconventional in the UK). ${ }^{8}$ However, the use of absolute measurements is suboptimal as abdominal dimensions inevitably vary (eg, in children, morbid obesity or distortion due to chronic ascites). As such, a relative approach for landmarks would seem more appropriate.

We propose several alterations to the authors' landmarks for paracentesis (figure 1). We advocate the use of McBurney's point as a rough surface landmark, guided by abdominal percussion, with the patient in supine position. This is located one-third of the distance between the right ASIS and the umbilicus, and is traditionally used to localise appendicitis.
The contralateral (left) McBurney's point is favoured, as the abdominal wall here is thinner, with deeper ascitic pool and lower theoretical risk of perforation as the sigmoid colon is more mobile than the fixed caecum. ${ }^{9}$ Care should be taken to avoid far lateral sites, engorged veins or previous scars. ${ }^{7}$ The landmarks can be shifted slightly laterally to account for scarring from regular paracentesis. We believe this approach to be safer and more anatomically correct in the absence of ultrasound guidance, and encourage a revision to Figure 4. However, this caveat should by no means detract from the commendable efforts by the authors in formulating these guidelines.

Keith Siau $\odot,{ }^{1}$ Naomi Robson, ${ }^{2}$ Steven Bollipo, ${ }^{3,4}$ Global Online Alliance for Liver Studies (GOAL), On behalf of the Global Online Alliance for Liver Studies (GOAL)

1 Department of Gastroenterology, The Dudley Group NHS Foundation Trust, Dudley, UK

${ }^{2}$ Biology Department, University of Toronto -

Mississauga, Mississauga, Ontario, Canada

${ }^{3}$ Department of Gastroenterology, John Hunter Hospital, Newcastle, New South Wales, Australia

${ }^{4} S$ chool of Medicine \& Public Health, The University of Newcastle, Callaghan, New South Wales, Australia

Correspondence to Dr Keith Siau, Department of Gastroenterology, The Dudley Group NHS Foundation Trust, Dudley, West Midlands, UK; keith@siau.org

Twitter Keith Siau @drkeithsiau, Naomi Robson @ robson_visuals and Steven Bollipo @stevenbollipo

Collaborators Global Online Alliance for Liver Studies (GOAL) collaborators:Devika Kapuria, Atoosa Rabiee, Gil Ben-Yakov, Goutham Kumar, Stephen Congly, Juan Turnes, Renumathy Dhanasekaran, Rashid N Lui.

Contributors All authors contributed equally.

Funding The authors have not declared a specific grant for this research from any funding agency in the public, commercial or not-for-profit sectors.

Competing interests None declared.
Patient and public involvement Patients and/or the public were not involved in the design, or conduct, or reporting, or dissemination plans of this research.

Patient consent for publication Not required.

Provenance and peer review Not commissioned; externally peer reviewed.

(c) Author(s) (or their employer(s)) 2021. No commercial re-use. See rights and permissions. Published by BMJ.

\section{Check for updates}

To cite Siau K, Robson N, Bollipo S, et al. Gut 2021;70:2216-2217.

Received 28 November 2020

Revised 16 December 2020

Accepted 16 December 2020

Published Online First 5 January 2021

Gut 2021;70:2216-2217. doi:10.1136/ gutjnl-2020-323731

\section{ORCID iD}

Keith Siau http://orcid.org/0000-0002-1273-9561

\section{REFERENCES}

1 Aithal GP, Palaniyappan N, China L, et al. Guidelines on the management of ascites in cirrhosis. Gut 2021:70:9-29.

2 Siau K. @drkeithsiau Guidelines on the management of ascites in cirrhosis. Twitter, 2020. Available: https:// twitter.com/drkeithsiau/status/1319682365082533890 [Accessed 16 Nov 2020].

3 Hurd WW, Bude RO, Delancey JO, et al. The location of abdominal wall blood vessels in relationship to abdominal landmarks apparent at laparoscopy. Am J Obstet Gynecol 1994;171:642-6.

4 Saber AA, Meslemani AM, Davis R, et al. Safety zones for anterior abdominal wall entry during laparoscopy: a CT scan mapping of epigastric vessels. Ann Surg 2004:239:182-5.

5 Joy P, Prithishkumar IJ, Isaac B. Clinical anatomy of the inferior epigastric artery with special relevance to invasive procedures of the anterior abdominal wall. J Minim Access Surg 2017:13:18-21.

6 Lee SY, Pormento JG, Koong HN. Abdominal paracentesis and thoracocentesis. Surg Laparosc Endosc Percutan Tech 2009;19:e32-5.

7 McGibbon A, Chen GI, Peltekian KM, et al. An evidencebased manual for abdominal paracentesis. Dig Dis Sci 2007:52:3307-15.

8 Thomsen TW, Shaffer RW, White B, et al. Paracentesis. N Eng/ J Med 2006;355:e21 https://www.nejm.org/doi/ full/10.1056/nejmvcm062234

9 Sakai H, Sheer TA, Mendler MH, et al. Choosing the location for non-image guided abdominal paracentesis. Liver Int 2005;25:984-6. 